\title{
Celastrol Dilates and Counteracts Ethanol-Induced Constriction of Cerebral Arteries ${ }^{[}$
}

\author{
- Kelsey North, Alexandria Slayden, Steven Mysiewicz, Anna Bukiya, and Alex Dopico \\ Department of Pharmacology, Addiction Science and Toxicology, College of Medicine, The University of Tennessee Health \\ Science Center, Memphis, Tennessee
}

Received June 5, 2020; accepted August 11, 2020

\section{ABSTRACT}

The increasing recognition of the role played by cerebral artery dysfunction in brain disorders has fueled the search for new cerebrovascular dilators. Celastrol, a natural triterpene undergoing clinical trials for treating obesity, exerts neuroprotection, which was linked to its antioxidant/anti-inflammatory activities. We previously showed that celastrol fit pharmacophore criteria for activating calcium- and voltage-gated potassium channels of large conductance (BK channels) made of subunits cloned from cerebrovascular smooth muscle (SM). These recombinant BK channels expressed in a heterologous system were activated by celastrol. Activation of native SM BK channels is well known to evoke cerebral artery dilation. Current data demonstrate that celastrol $(1-100 \mu \mathrm{M})$ dilates de-endothelialized, ex vivo pressurized middle cerebral arteries (MCAs) from rats, with $\mathrm{EC}_{50}=45 \mu \mathrm{M}$ and maximal effective concentration $\left(E_{\max }\right)=100 \mu \mathrm{M}$ and with MCA diameter reaching a $10 \%$ increase over vehicle-containing, time-matched values $(P<0.05)$. A similar vasodilatory efficacy is achieved when celastrol is probed on MCA segments with intact endothelium. Selective BK blocking with $1 \mu \mathrm{M}$ paxilline blunts celastrol vasodilation. Similar blunting is achieved with $0.8 \mathrm{mM} 4-$ aminopirydine, which blocks voltage-gated $\mathrm{K}^{+}$channels other than BK. Using an in vivo rat cranial window, we further demonstrate that intracarotid injections of $45 \mu \mathrm{M}$ celastrol into pial arteries branching from MCA mimics celastrol ex vivo action. MCA constriction by ethanol concentrations reached in blood during moderate-heavy alcohol drinking $(50 \mathrm{mM})$, which involves SM BK inhibition, is both prevented and reverted by celastrol. We conclude that celastrol could be an effective cerebrovascular dilator and antagonist of alcohol-induced cerebrovascular constriction, with its efficacy being uncompromised by conditions that disrupt endothelial and/or BK function.

\section{SIGNIFICANCE STATEMENT}

Our study demonstrates for the first time that celastrol significantly dilates rat cerebral arteries both ex vivo and in vivo and both prevents and reverses ethanol-induced cerebral artery constriction. Celastrol actions are endothelium-independent but mediated through voltage-gated $\left(\mathrm{K}_{\mathrm{V}}\right)$ and calcium- and voltagegated potassium channel of large conductance $(\mathrm{BK}) \mathrm{K}^{+}$channels. This makes celastrol an appealing new agent to evoke cerebrovascular dilation under conditions in which endothelial and/or BK channel function are impaired.

\section{Introduction}

Several facts drive the continuous search for effective and safe cerebrovascular dilators. First, central neurons critically depend on oxygen delivery for their metabolic needs (Hui et al., 2017). This makes the brain particularly vulnerable to widespread pathologic conditions in which ischemia plays a central role in the genesis and/or progression of the disease. Indeed, stroke is the fourth cause of death and first cause of longterm disability in the United States (www.americanheart.org; Beaglehole and Jackson, 1992). In ischemic stroke, increased arterial tone with a consequent decrease in cerebral artery diameter has often been reported (Zakhari, 1997; Wilkinson and Cockcroft, 1998; Cipolla and Curry, 2002). In

This work was supported by National Institutes of Health National Institute on Alcohol Abuse and Alcoholism [Grant R37-AA11560] (to A.D.) and National Heart, Lung, and Blood Institute [Grant R01-HL-147315] (to A.D. and A.B.). https://doi.org/10.1124/jpet.120.000152.

S This article has supplemental material available at jpet.aspetjournals.org. addition, cerebral artery constriction often follows brain hemorrhagic events (http://www.americanheart.org/downloadable/ heart/1177593979236FS06INTL07.pdf; Macdonald and Weir, 2001; Agrawal et al., 2009). Moreover, pharmaceutical intervention during the ischemic penumbra associated with cerebrovascular events presents an opportunity for neuroprotection and tissue repair (Ramos-Cabrer et al., 2011). Second, there is an increasing recognition of the central role that disruption of cerebral artery function exerts on cognitive function and in the pathology and evolution of cognitive disorders, including an increased risk of Alzheimer disease (Schreiber et al., 2005; Villarreal et al., 2014), and in systemic arterial hypertension linked to cognitive deficits (Brown, 1999; Román, 2003; Villella and Cho, 2015). Third, genesis and progression of prevalent brain conditions distinct from cognitive disorders are also linked to cerebral artery dysfunction, including late-onset epilepsy (Richardson and Dodge, 1954) and some forms of migraines (Edmeads, 1977; Olesen et al., 1982; Lauritzen et al., 1983). Last but not least, cerebrovascular disorders contribute

ABBREVIATIONS: 4-AP, 4-aminopirydine; BK channel, calcium- and voltage-gated potassium channel of large conductance; $\mathrm{E}_{\text {max }}$, maximal effective concentration; HENA sodium, 3-hydroxyolean-12-en-30-oate; $\mathrm{K}_{\mathrm{v}}$ channel, voltage-gated potassium channel; MCA, middle cerebral artery; PSS, physiologic sodium saline; SM, smooth muscle. 
to the morbidity and disability associated with illicit drug use. Indeed, drug abusers have an increased risk of both hemorrhagic and ischemic stroke (Fonseca and Ferro, 2013). In particular, binge drinking, which constitutes the most common pattern of excessive alcohol consumption in the United States (https://www.cdc.gov/alcohol/ fact-sheets/binge-drinking.htm), is associated with an increased prevalence of both ischemic and hemorrhagic stroke (Zakhari, 1997; Reynolds et al., 2003; FernándezSolá, 2015; Klatsky, 2015). Ethanol concentrations reached in blood during binge drinking constrict cerebral arteries in a wide variety of species, including humans, both ex vivo and in vivo (Altura et al., 1983; Altura, 1984; Altura and Altura, 1984; Anderson et al., 1993; Zhang et al., 1993; Gordon and Zagotta, 1995; Cudd et al., 1996; Yang et al., 2001; Liu et al., 2004; Bukiya et al., 2009; Simakova et al., 2017). This ethanol action results from drug-induced inhibition of cerebrovascular SM K ${ }^{+}$channels of the BK type (Liu et al., 2004; Bukiya et al., 2009). This finding is expected from the fact that these channels, upon plasma membrane depolarization and/or intracellular $\mathrm{Ca}^{2+}$ driven activation, generate outward currents that limit depolarization and decrease global intracellular $\left[\mathrm{Ca}^{2+}\right]$, leading to cerebrovascular myocyte relaxation and cerebral artery dilation (Brayden and Nelson, 1992; Kamouchi et al., 2002; Dopico et al., 2018).

In the 1980 s and $1990 \mathrm{~s}, \mathrm{~K}^{+}$channel "openers"-i.e., drugs that increase $\mathrm{K}^{+}$channel activity and thus repolarize the $\mathrm{SM}$ membrane, leading to tissue relaxation and vasodilationwere received with great enthusiasm as a new type of vasodilator. However, most of these drugs target ATPsensitive potassium channels $\left(\mathrm{K}_{\mathrm{ATP}}\right)$ and thus inhibit insulin secretion, which led to their reconsideration for widespread use as vasodilators (Mannhold, 2004; Hansen, 2006). In turn, BK channel activators usually target the ubiquitously expressed channel-forming $\mathrm{BK} \alpha$ subunit and/ or affect channels with pores similar to BK, like the noninactivating voltage-gated potassium channel, subfamily $\mathrm{Q}$ member 2 (KCNQ2), which leads to modification of excitability in tissues other than vascular SM (Jensen, 2002; Bentzen et al., 2006; Nardi and Olesen, 2008).

Celastrol (Fig. 1) is a natural triterpene currently undergoing phase 1 clinical trials as a therapeutic agent for treating obesity because of its powerful leptin-sensitizing ability (Liu et al., 2015; Ma et al., 2015). Celastrol also exerts neuroprotection, which has been linked to its antioxidant and anti-inflammatory activities (Allison et al., 2001; Cleren et al., 2005; Kiaei et al., 2005; Paris et al., 2010). Remarkably, our group has identified that celastrol fits pharmacophore criteria for activation of BK channels that include regulatory subunits abundant in cerebrovascular SM and has further demonstrated that ex vivo exposure of these recombinant heteromeric BKs in a heterologous expression system could be activated by celastrol (McMillan et al., 2014). The aim of this study is to determine whether 1) celastrol dilates cerebral arteries both ex vivo and in vivo; 2) this action requires the vascular endothelium or, rather, involves SM targets; 3) celastrol-induced cerebral dilation specifically involves BKs; and 4) celastrol is able to counteract cerebral artery constriction evoked by ethanol concentrations found in blood during binge drinking.

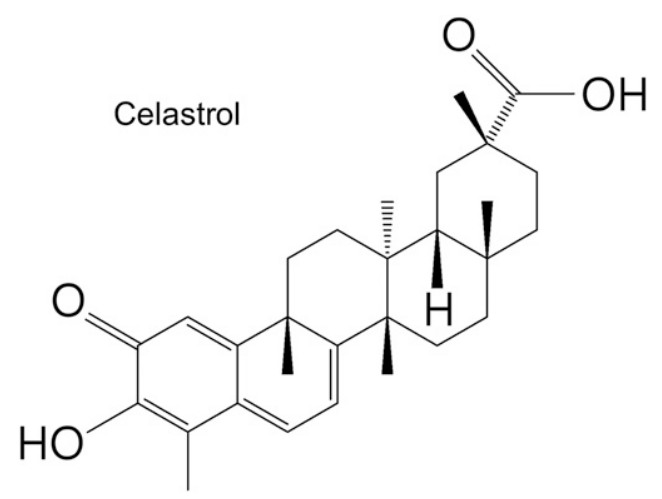

Fig. 1. Chemical structure of celastrol, or 3-hydroxy-9 $\beta, 13 \alpha$-dimethyl-2oxo-24,25,26-trinoroleana-1(10),3,5,7-tetraen-29-oic acid. Celastrol, a pentacyclic triterpenoid that belongs to the family of quinone methides, meets major pharmacophore criteria for ligands that increase the activity of BKs made of subunits prevalent in vascular SM [see main text and McMillan et al. (2014)].

\section{Material and Methods}

Ethical Aspects of Research. The care of animals and experimental protocols were reviewed and approved by the Institutional Animal Care and Use Committee of the University of Tennessee Health Science Center, which is an institution accredited by the Association for Assessment and Accreditation of Laboratory Animal Care International.

Cerebral Artery Diameter Measurements Ex Vivo. Adult male Sprague-Dawley rats ( $250 \mathrm{~g})$ were euthanized by decapitation under deep anesthesia via isoflurane inhalation. Middle cerebral arteries (MCAs) were dissected out from rat brains on ice under microscope (SMZ645; Nikon), and each artery was cut into two segments. Each segment end was cannulated onto glass cannulas in a perfusion chamber designed ad hoc. When required by experimental design, the endothelium was removed by passing an air bubble through the vessel lumen for 90 seconds prior to vessel cannulation. This method is highly effective for removing the endothelial layer, with the lack of endothelium being verified by comparing the efficacy of endothelium-dependent versus endothelium-independent vasodilators as previously described (Liu et al., 2004). Using a Dynamax RP-1 peristaltic pump (Rainin Instrument), the chamber was continuously perfused at a rate of $3.75 \mathrm{ml} / \mathrm{min}$ with physiologic sodium saline (PSS) with the following composition (millimolars): $119 \mathrm{NaCl}, 4.7 \mathrm{KCl}, 1.2 \mathrm{KH}_{2} \mathrm{PO}_{4}, 1.6$ $\mathrm{CaCl}_{2}, 1.2 \mathrm{MgSO}_{4}, 0.023$ EDTA, 11 glucose, and $24 \mathrm{NaHCO}_{3}$. PSS was equilibrated at pH 7.4 with a $21 / 5 / 74 \%$ mixture of $\mathrm{O}_{2} / \mathrm{CO}_{2} / \mathrm{N}_{2}$ gases and maintained at $35-37^{\circ} \mathrm{C}$. Arteries were continuously monitored with a charge-coupled device camera (41AU02; DMK) attached to the vertical pole of an inverted microscope (TS100; Nikon Eclipse or AE31; Motic). The artery wall external (outer) diameter was measured using the automatic edge-detection function of IonWizard software (IonOptics) and digitized at $1 \mathrm{~Hz}$. Changes in intravascular pressure were achieved by elevating an attached reservoir filled with PSS and monitored using a pressure transducer (Living Systems Instrumentation). Arteries were first incubated at an intravascular pressure of $10 \mathrm{~mm} \mathrm{Hg}$ for 10 minutes. Then, intravascular pressure was increased to $60 \mathrm{~mm} \mathrm{Hg}$ until arteries developed myogenic tone (Liu et al., 2004). Pressure was held steady throughout the experiment to ensure myogenic tone maintenance. Drugs were dissolved to make stock solutions, diluted in PSS to final concentration, and applied to the artery via chamber perfusion. To avoid any possible receptor desensitization related to repeated/protracted exposure to the ligand (particularly when dealing with ethanol-BK channel interactions; Dopico and Lovinger, 2009; Dopico et al., 2018), every artery diameter measurement under a given condition was obtained from a unique arterial segment. 
Cerebral Artery Diameter In Vivo Measurement through a Cranial Window. Adult male Sprague-Dawley rats (250-350 g) were anesthetized with ketamine/xylazine mixture $(91 / 9 \mathrm{mg} / \mathrm{kg}$ of weight) and kept anesthetized for the duration of the experiment with subsequent ketamine doses $(50 \mathrm{mg} / \mathrm{kg}$ of weight) as needed. The catheter was inserted in the carotid artery so that the infusion went straight to the brain rather than toward the thoracic cavity. A cranial window (Busija and Leffler, 1991) was made on the side where the catheter had been inserted; thus, the area above the zygomatic arch, between the ear and the eye of the skull, was cleared of skin and underlying tissue, and then the bone was removed using a Dremel 4000. The exposed arteries branching out from the MCA were monitored using a Leica MC170 HD microscope with a mounted camera (M125 C; Leica) connected to a computer monitor. Drugs were diluted to their final concentration in sodium saline $(0.9 \% \mathrm{NaCl})$ and administered via catheter at $1 \mathrm{ml} / 250 \mathrm{~g}$ of weight. Cranial window images before and after drug administration were acquired every 60 seconds for subsequent analysis (see below).

Chemicals. Celastrol was purchased from Cayman Chemical. Ethanol (200 proof; E7023) and all other chemicals were purchased from Sigma-Aldrich. Celastrol was dissolved in DMSO to make a stock solution at $33.3 \mathrm{mM}$, which was stored in DMSO at $-20^{\circ} \mathrm{C}$ for up to 1 year. Celastrol stock solution and ethanol were diluted into PSS or saline solution to reach final concentrations immediately before experimental use. Each pressurized artery ex vivo or each animal during in vivo experiments was only exposed to celastrol, ethanol, or their combination once to avoid possible use-dependent desensitization.

Data Analysis. Ex vivo MCA diameter data were analyzed using IonWizard 4.4 software (IonOptix) by continuous recording in real time of the exterior diameter of cannulated artery segments. Each data point was collected on individual artery segments to avoid desensitization and false repetitions. Changes in artery diameter obtained from cranial window experiments were determined using ImageJ software (ImageJ 1.52a, https://imagej.nih.gov/ij/download. $\mathrm{html}$ ). The value for basal artery diameter (i.e., diameter before drug application) was obtained by averaging diameter values from the same arterial segment during 3 minutes of recording immediately before drug application. Drug-induced effects in arterial diameter were determined at the maximal, steady drug concentration reached in the chamber before the perfusion was switched to another drug or a washout. The concentration-response curve data obtained from ex vivo experiments were fitted to the following Boltzmann function: $y=\frac{A_{1}-A_{2}}{1+e^{\left(x-x_{0}\right)} / d x}+A_{2}$ (Origin 2020). Statistical analysis was performed using InStat 3.05 software (GraphPad). Statistical methods included either Kruskal-Wallis test or Mann-Whitney $U$ test, according to experimental design. In all cases, significance was set at $P<0.05$. Data were expressed as means \pm S.D. In each experimental group, individual artery segments ex vivo or MCA diameter recordings in vivo were obtained from different animals. Final plotting and fitting of data were conducted using the Origin 2020 software program (Origin Laboratory Corp.).

\section{Results}

Celastrol Dilates Isolated, Pressurized Middle Cerebral Arteries in Both Presence and Absence of Endothelium. To determine whether celastrol is a vasoactive compound, isolated MCA segments were pressurized as described in Material and Methods and exposed to various concentrations of celastrol $(1-100 \mu \mathrm{M})$. For all other experiments in this study, we chose MCA because 1-MCA perfuses more brain territories than the other branches of Willis' circle (Lee, 1995; Lehecka et al., 2012); 2-MCA tone and diameter modifications are associated with numerous cerebrovascular, including ischemic, disorders (Cipolla and
Curry, 2002; González Delgado and Bogousslavsky, 2012; Krafft et al., 2012); and 3-MCA has been used in our previous studies of ethanol-induced constriction of cerebral arteries and its mediation by SM BK channels (Liu et al., 2004; Bukiya et al., 2009), as well as to demonstrate the key role of these $\mathrm{K}^{+}$channels as effectors of drug-induced cerebrovascular dilation (Bukiya et al., 2007, 2013). Viability of isolated MCA segments was determined by evaluating their contraction in response to $60 \mathrm{mM} \mathrm{KCl}$-induced depolarization (which serves as reader of close-to-maximal, depolarization-driven constriction) and their relaxation in response to $\mathrm{Ca}^{2+}$-free PSS (which serves as reader of passive diameter) at the beginning and end of each experiment, respectively. Changes in diameter from its basal value in response to $60 \mathrm{mM} \mathrm{KCl}$ and $\mathrm{Ca}^{2+}$-free PSS are shown in Supplemental Fig. 1. This figure also documents the small variability in diameter measurement in the absence of drugs at time-matched intervals. MCA segments that failed to appropriately respond to $60 \mathrm{mM} \mathrm{KCl}$ and $\mathrm{Ca}^{2+}$-free PSS were not included for data analysis (Liu et al., 2004; Bukiya et al., 2007, 2009). Celastrol evoked an increase in MCA diameter that was fully reversible at all concentrations upon washout with PSS (Fig. 2A). Celastrol action was concentration-dependent, with $\mathrm{EC}_{50}=10 \mu \mathrm{M}$ and maximal dilation reached at $45 \mu \mathrm{M}$, at which diameter increased by $10.4 \% \pm 4.2 \%$ of control values (Fig. $2, \mathrm{~A}$ and $\mathrm{B}$; reduced $\chi^{2}=0.2$, $\left.\mathrm{R}^{2}=0.98\right)$.

The possible contribution of endothelium to celastrolinduced MCA dilation was determined by obtaining a concentration-response curve to this drug in MCA segments in which the endothelium was mechanically removed prior to vessel pressurization and drug exposure (see Material and Methods). MCA segment viability was determined as described above for endothelium-intact vessels. As found for MCA segments with intact endothelium, 1-100 $\mu \mathrm{M}$ celastrol reversibly dilated deendothelialized MCAs in a concentration-dependent manner, with $\mathrm{EC}_{50}=45 \mu \mathrm{M}$ and $\mathrm{E}_{\max }$ at $100 \mu \mathrm{M}$, at which diameter reached $9.1 \% \pm 3.2 \%$ of control (Fig. $2, \mathrm{C}$ and $\mathrm{D}$; reduced $\left.\chi^{2}=0.04, R^{2}=0.99\right)$. Together, these data indicate that the endothelium is not necessary for celastrol to evoke MCA dilation, but extraendothelial drug targets, most likely located in the vascular SM, suffice (see next section). Moreover, the vasodilatory efficacy of celastrol in intact and de-endothelialized MCAs was indistinguishable, underscoring the possible therapeutic efficacy of celastrol as a cerebrovascular dilator in conditions in which endothelial function is impaired.

However, neither $\mathrm{EC}_{50}$ nor $\mathrm{E}_{\max }$ values were identical in intact versus de-endothelialized MCA, suggesting a modulatory action of endothelium on drug action. For example, $\mathrm{EC}_{50}$ values obtained after running a single fit of averaged data to a Boltzmann function rendered $8.8 \pm 1.3$ and $40.3 \pm 2.2 \mu \mathrm{M}$ for intact and de-endothelialized, respectively. Indeed, celastrol effects at equipotent concentrations $(10 \mu \mathrm{M}$ in intact vs. $45 \mu \mathrm{M}$ in de-endothelialized MCA) are statistically different $(P=0.01$; Kruskal-Wallis test). Finally, Fig. 2, B and D also show that celastrol $\mathrm{E}_{\max }$ clearly differs in intact versus de-endothelialized MCA ( $\sim 45$ vs. $\sim 100 \mu \mathrm{M}$, respectively). To further compare drug action in intact versus de-endothelialized MCA, we fitted celastrol concentration-MCA dilation data to an equation of the type: $n_{\mathrm{H}}=\log _{10}(81) / \log _{10}\left(\mathrm{EC}_{90} / \mathrm{EC}_{10}\right)$, where $n_{\mathrm{H}}$ is the Hill coefficient, and $\mathrm{EC}_{90}$ and $\mathrm{EC}_{10}$ are the concentrations to 
A

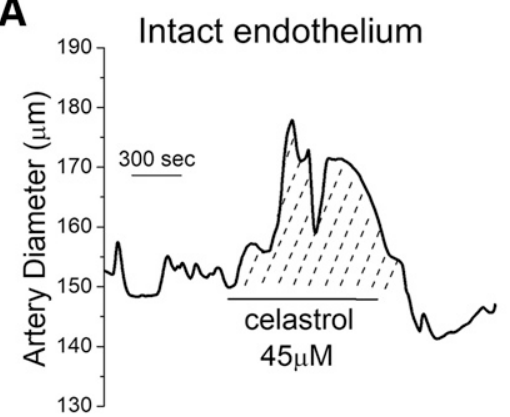

B

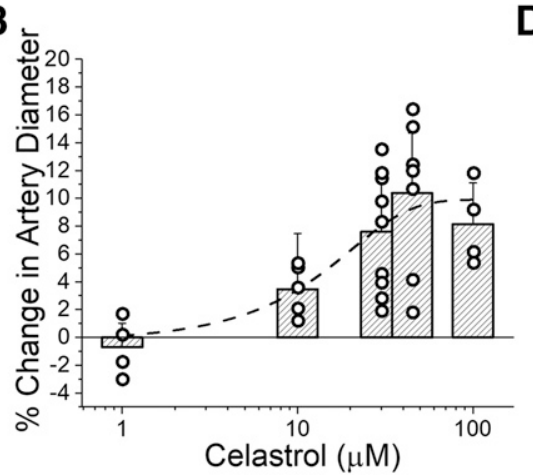

C

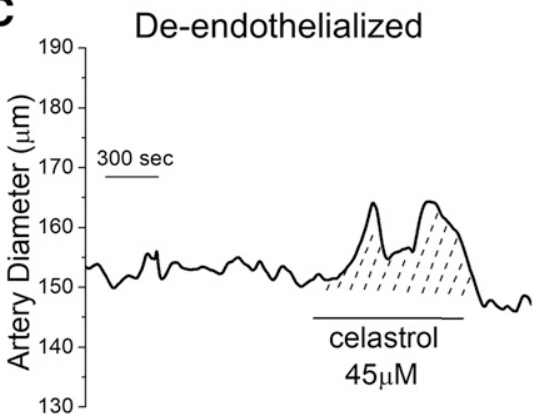

D

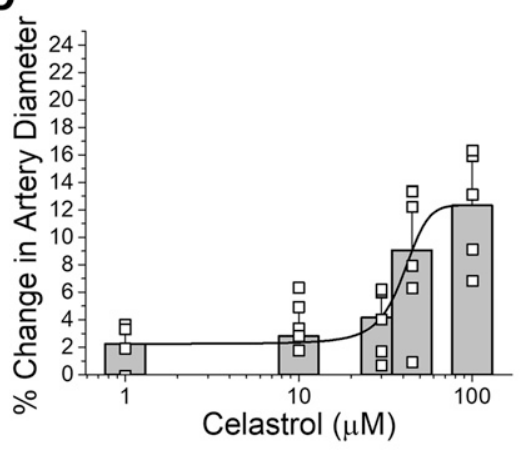

Fig. 2. Celastrol is an endothelium-independent dilator of cerebral arteries ex vivo. (A) Diameter trace showing dilation of pressurized MCA segments with intact endothelium in the presence of $45 \mu \mathrm{M}$ celastrol. Here and in all other figures, celastrol-induced dilation (area under the curve) is highlighted by tilted dashed lines. (B) Celastrol-driven percent changes in rat MCA with intact endothelium; data are fitted to a Boltzmann function. (C) Diameter trace showing dilation of deendothelialized, pressurized MCA segments in the presence of $100 \mu \mathrm{M}$ celastrol. (D) Celastrol-driven percent changes in de-endothelialized MCA; data are fitted to a Boltzmann function. Here and in all figures, deviation from averaged value is shown as S.D. produce the $10 \%$ and $90 \%$ of the maximal response, respectively (Altszyler et al., 2017). Celastrol $n_{\mathrm{H}}$ values for dilating MCA were higher than 1 and almost identical in de-endothelialized and intact arteries: 1.98 and 2.01, respectively. This result led us to speculate that multiple receptor sites of extraendothelial location participate in celastrol action and/or there is positive cooperativity in celastrol interaction with a homogeneous population of receptors.

Celastrol Is Able to Dilate Middle Cerebral Arteries through Involvement of Extraendothelial Potassium Channels. Since celastrol is effective in dilating intact and de-endothelialized MCAs, the primary cellular mediators of its vasodilatory action should be of extraendothelial location. First, in de-endothelialized arteries, SM accounts for up to $70 \%$ of total tissue (Lee, 1995). Second, we aimed at obtaining novel $\mathrm{K}^{+}$ channel openers. Lastly, our previous data (McMillan et al., 2014) from patch-clamp studies using a heterologous expression system (Xenopus laevis oocytes) demonstrated that celastrol at micromolar levels could potentiate currents mediated by BK channel-forming slo1 proteins (cbv1 isoform: cloned from rat cerebral artery SM; AY330293) (Liu et al., 2004) and SMabundant $\beta 1$ regulatory subunits (FJ154955). Therefore, we next tested whether different $\mathrm{K}^{+}$channel populations known to be present in cerebrovascular smooth muscle participated in celastrol-induced dilation of de-endothelialized MCAs. Thus, we evaluated celastrol action in the presence of either paxilline at a concentration that selectively blocks BK channels (1 $\mu \mathrm{M}$; Strøbaek et al., 1996; Zhou and Lingle, 2014) or 4aminopyridine (4-AP) at a concentration that blocks $\mathrm{K}_{\mathrm{V}}$ channels other than the BK type (0.8 mM; Liu et al., 2004; Robertson and Nelson, 1994). In de-endothelialized MCA segments, paxilline and 4-AP each significantly decreased the dilation by $100 \mu \mathrm{M}$ celastrol from $11.7 \% \pm 2.6 \%$ to $-0.5 \% \pm 1.2 \%$ and to $0.6 \% \pm 2.1 \%$, respectively $(P=0.000021$; Fig. $3, \mathrm{C}$ and $\mathrm{D})$. Thus, each $\mathrm{K}^{+}$channel blocker is sufficient, although neither is necessary, to blunt endothelium-independent, celastrolinduced dilation of MCAs. On a separate set of experiments, we decided first to apply each $\mathrm{K}^{+}$channel blocker followed by celastrol. As expected from the active states of smooth muscle $\mathrm{BK}$ and $\mathrm{K}_{\mathrm{V}}$ channels in the pressurized MCA and their contribution to artery diameter regulation, application of each blocker produced a modest but significant constriction of de-endothelialized vessels. Moreover, such treatments prevented celastrol from evoking MCA constriction (Fig. 4, $\mathrm{C}$ and $\mathrm{D})$. This result further underscores the role of such populations of smooth muscle $\mathrm{K}^{+}$channels in celastrolinduced vasodilation. Collectively, celastrol-blocker data in de-endothelialized MCA seem to indicate that $\mathrm{K}^{+}$channelinduced repolarization in $\mathrm{SM}$, whether via $\mathrm{BK}$ or $\mathrm{K}_{\mathrm{V}}$ channels, is the primary mechanism underlying celastrol dilation of cerebral arteries (see Discussion).

As was found for de-endothelialized vessels, paxilline and 4-AP significantly blunted the vasodilation evoked by $100 \mu \mathrm{M}$ celastrol when evaluated in intact MCAs: from $10.4 \% \pm 4.3 \%$ to $0.8 \% \pm 2.0 \%$ and to $0.8 \% \pm 4.7 \%$, respectively $(P=0.0009$; Fig. 3 , $\mathrm{A}$ and $\mathrm{B})$. In addition, as was found for de-endothelialized vessels, each blocker was able to induce a modest yet significant constriction of the intact MCA while fully preventing celastrol from dilating these vessels (Fig. 4, C and D). The efficacies of paxilline and 4-AP to counteract celastrol action, whether the $\mathrm{K}^{+}$ channel blockers were administered with (Fig. 3) or prior (Fig. 4) to administering the triterpene, were indistinguishable from those found in de-endothelialized arteries. Collectively, our data indicate that the endothelium does not exert any major modulation of $\mathrm{K}^{+}$channels as effectors of celastrol-induced dilation of MCAs.

Celastrol Dilates Cerebral Arteries In Vivo. To determine whether the vasodilatory effect of celastrol on cerebral arteries remains at the organismal level, we used the cranial window methodology and evaluated celastrol-induced 

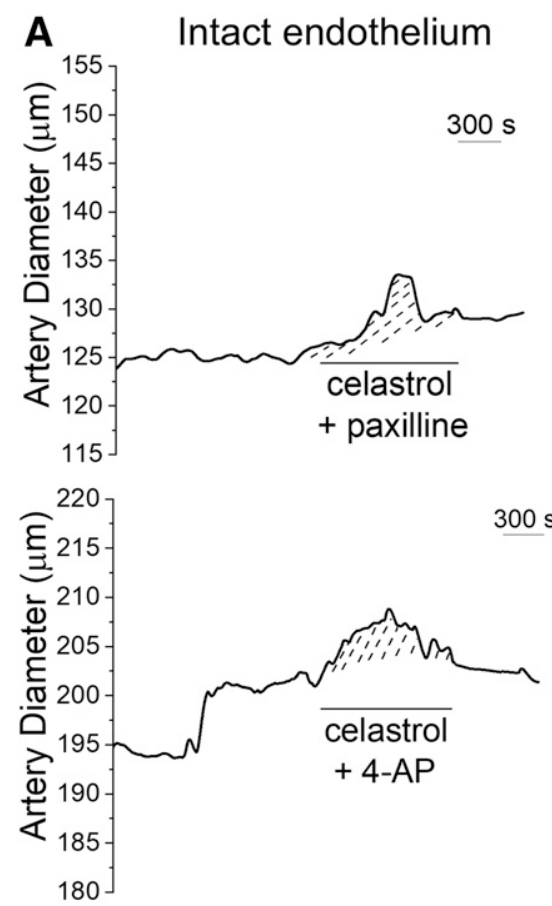

B



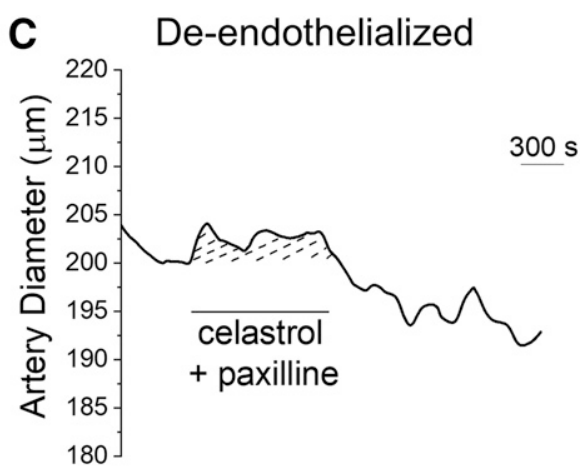



D

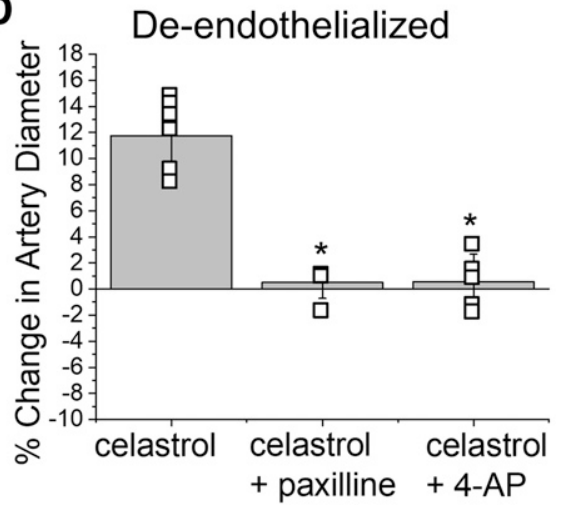

Fig. 3. Simultaneous in vitro exposure to celastrol and blockers of either $\mathrm{BK}$ or $\mathrm{K}_{\mathrm{V}}$ (other than BK) channels prevents the triterpene from dilating MCA, whether probed in intact or deendothelialized vessels. (A) Diameter trace showing response of pressurized MCA segments with intact endothelium to application of $45 \mu \mathrm{M}$ celastrol and $1 \mu \mathrm{M}$ paxilline mixture (top) as well as 45 $\mu \mathrm{M}$ celastrol and $0.8 \mathrm{mM}$ 4-AP mixture (bottom). (B) Comparison of percent changes in rat MCA with intact endothelium in response to 45 $\mu \mathrm{M}$ celastrol as opposed to $45 \mu \mathrm{M}$ celastrol mixtures with either $1 \mu \mathrm{M}$ paxilline or $0.8 \mathrm{mM}$ 4-AP. *Different from $45 \mu \mathrm{M}$ celastrol $(P=0.00098$, Kruskal-Wallis). (C) Diameter traces showing responses of de-endothelialized pressurized MCA of rat in the presence of $100 \mu \mathrm{M}$ celastrol and $1 \mu \mathrm{M}$ paxilline mixture (top) or $100 \mu \mathrm{M}$ celastrol and $0.8 \mathrm{mM}$ 4-AP mixture (bottom). (D) Comparison of percent changes in rat de-endothelialized MCA in response to $100 \mu \mathrm{M}$ celastrol as opposed to $100 \mu \mathrm{M}$ celastrol mixtures with either $1 \mu \mathrm{M}$ paxilline or $0.8 \mathrm{mM} 4-\mathrm{AP}$. *Different from celastrol $(P=0.00213 ;$ Kruskal-Wallis $)$. cerebrovascular dilation in anesthetized rats. This technique allows us to continuously monitor the diameter of pial resistance-size arteries $(>100 \mu \mathrm{m}$ in external diameter) that arise from the MCA and constitute essential vessels for maintaining proper blood flow to the brain (Baumbach and Heistad, 1985). For each experiment, baseline images of MCAs were captured prior to any drug application and used for reference of the fold changes in MCA diameter throughout each experiment. All drugs were infused toward the cerebral circulation using an intracarotid artery catheter as detailed in Material and Methods. Representative images shown in Fig. 5A (bottom panels) document that a bolus injection of $45 \mu \mathrm{M}$ celastrol at minute 1 , followed by a saline injection at minute 4 , resulted in MCA dilation, with average maximal dilation represented by the last bottom panel, which shows an MCA diameter image at minute 12 of the experiment. An identical pattern was replicated in five other MCAs. One experiment out of seven, however, was excluded from quantitative analysis because of the MCA's unusual biphasic response (initial constriction followed by vasodilation). In all experiments, vehicle (DMSO) failed to induce any change in MCA diameter. The lack of vehicle action is underscored by the time-paired top panels of Fig. 5A. Averaged data shown in Fig. 5B reveal that celastrol infusion-induced MCA dilation is evident immediately upon bolus injection of the drug, evoking an increase of $5 \%$ in MCA diameter and further increasing to $10 \% 2$ minutes later (i.e., minute 3 in the abscissa), reaching statistical significance $(P<0.05)$. Celastrol-induced dilation, albeit with some quantitative oscillation, remains sustained throughout the whole 12 minutes of recording and is statistically different $(P<0.05)$ after minute 7 of infusion when compared with time- and volume-matched injections of celastrol's vehicle followed by saline. Remarkably, time-averaged change in diameter induced by intracarotid administration of celastrol to anesthetized animals ( $~ 7 \%$ increase in MCA diameter) is similar to that shown in isolated MCA segments (Figs. 2 and 5). These data indicate that celastrol local metabolism, binding to circulating factors, or putative interactions with the anesthetic agents do not evidently affect the drug vasodilatory efficacy. 
A


B

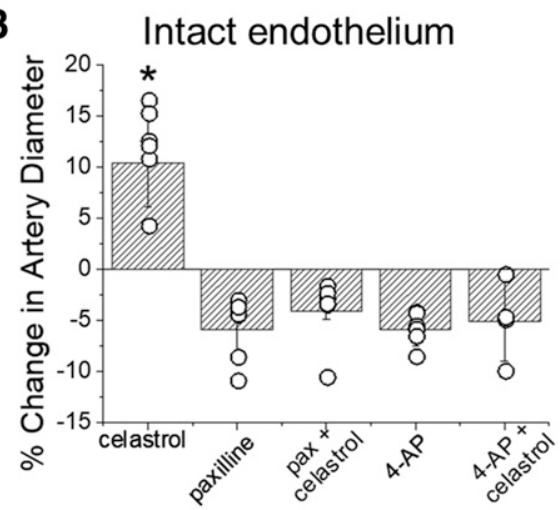





D

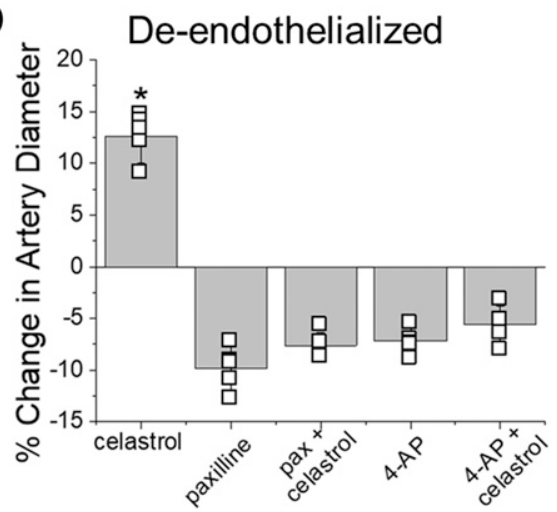

Fig. 4. Previous in vitro exposure to either BK or $\mathrm{K}_{\mathrm{V}}$ (other than BK) channels prevents celastrol from dilating MCA segments, whether probed in intact or de-endothelialized vessels. (A) Diameter trace showing response of pressurized MCA segments with intact endothelium to application of $1 \mu \mathrm{M}$ paxilline followed by $1 \mu \mathrm{M}$ paxilline and $45 \mu \mathrm{M}$ celastrol mixture (top) as well as $0.8 \mathrm{mM}$ 4-AP followed by 4-AP and $45 \mu \mathrm{M}$ celastrol mixture (bottom). (B) Comparison of percent changes in rat MCA with intact endothelium in response to $45 \mu \mathrm{M}$ celastrol, $1 \mu \mathrm{M}$ paxilline, paxilline and celastrol mixture (pax + celastrol), 4-AP, and 4-AP and celastrol mixture. ${ }^{*}$ Different from $45 \mu \mathrm{M}$ celastrol ( $P=0.0000014$, Kruskal-Wallis). (C) Diameter trace showing response of de-endothelialized MCA segments in response to the application of 1 $\mu \mathrm{M}$ paxilline followed by a mixture of paxilline and $100 \mu \mathrm{M}$ celastrol (top) as well as $0.8 \mathrm{mM}$ 4-AP followed by 4-AP and $100 \mu \mathrm{M}$ celastrol mixture (bottom). (D) Comparison of percent changes in de-endothelialized rat MCAs in response to $100 \mu \mathrm{M}$ celastrol, $1 \mu \mathrm{M}$ paxilline, paxilline and celastrol mixture, 4-AP, and 4-AP with celastrol mixture. *Different from $100 \mu \mathrm{M}$ celastrol $(P=0.00000219$, Kruskal-Wallis).
Celastrol Antagonizes Alcohol-Induced Constriction of Middle Cerebral Arteries Ex Vivo Independently of a Functional Endothelium. We have previously documented that rat MCA is reversibly constricted by ethanol (10-100 mM), a drug action that involves several ion channel populations present in cerebrovascular SM, such as transient receptor potential cation channel subfamily V member 1 (TRPV1) (North et al., 2018), voltage-gated $\mathrm{K}^{+}$of the $\mathrm{BK}$ type, and ryanodine receptor type 2 channels (Liu et al., 2004). After documenting that celastrol vasodilation of MCA involved BK channels (Fig. 3), we explored whether celastrol could overcome endotheliumindependent, ethanol-induced constriction of MCA. Thus, celastrol's ability to antagonize alcohol-induced MCA constriction was first tested ex vivo using pressurized, de-endothelialized MCA segments. As previously reported using de-endothelialized MCAs from rat (Liu et al., 2004) or mouse (Bukiya et al., 2009), ethanol (10-100 $\mathrm{mM})$ evoked a concentration-dependent constriction, which is shown in representative traces (Fig. 6, D and E) and both scattered individual and averaged data (Fig. 6F). The ethanol concentration range used in these experiments spans from blood alcohol levels that are considered legal intoxication in most US states (17 mM) to those that are usually lethal in naïve humans (100 mM) (Diamond, 1992). Remarkably, celastrol at maximal effective concentrations $(100 \mu \mathrm{M})$ fully antagonized the alcohol-induced artery constriction across the whole range of ethanol concentrations probed, as shown in representative traces (Fig. 6, D and E) and both scattered and averaged data (Fig. 6F). These results demonstrate that celastrol can antagonize ethanol-induced constriction of cerebral arteries in the absence of a functional endothelium, which may have relevance regarding alcohol consumption in subjects with conditions associated with endothelial dysfunction (see Discussion).

We next investigated celastrol antagonism of ethanol action on MCA diameter using intact, isolated vessels. As previously reported (Liu et al., 2004), ethanol (17 mM) constricted intact MCA in a concentration-dependent manner, which is shown in representative traces (Fig. 6, A and B) and both scattered individual and averaged data (Fig. 6C). In these vessels, $45 \mu \mathrm{M}$ celastrol was not only able to suppress ethanolinduced vasoconstriction but, in most cases, actually reverted 
A

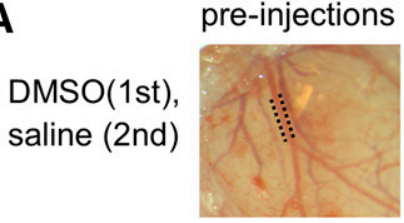

pre-injections

celastrol (1st),

saline (2nd)



minute 4

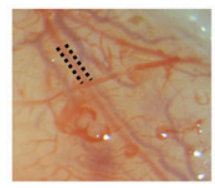

minute 12

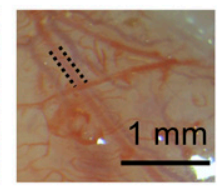

B



Fig. 5. Celastrol dilates cerebral arteries in vivo. (A) Cranial window images of rat MCA prior to any infusions (base) at 4 minutes after infusions of either celastrol's vehicle (top row of images) or time-matched infusion of $45 \mu \mathrm{M}$ celastrol (bottom row of images). In both cases, at minute 4, animals were infused with a bolus of saline to provide a volumematched control for experimental groups involving alcohol (see Fig. 7) Dashed lines highlight area MCA diameter changes. A single experiment for the celastrol + saline group out of a total of seven was not considered for analysis because of its highly unusual biphasic response (constriction followed by dilation). (B) Averaged fold changes in MCA diameter for each minute of recording compared with baseline diameter determined from image taken immediately prior to any infusion. Horizontal dashed line points at 1 , meaning there is no change in artery diameter. $N=6$ for each group; individual $N$ was obtained from a separate rat. *Different from vehicle at the corresponding time point $(P<0.05$, Mann-Whitney $U$ test $)$.

ethanol action to dilation (Fig. 6, A and C). It is thus likely that some endothelial mediator(s) amplifies celastrol antagonism against ethanol, leading to speculation that the endothelium, although not a primary mediator, can modulate celastrol's cerebrovascular actions.

Celastrol Antagonizes Alcohol-Induced Cerebral Artery Constriction In Vivo. To determine whether celastrol antagonism of ethanol action on cerebral arteries remained in the live animals, we used a similar approach to that used to probe celastrol itself on MCA. Thus, the effect of $50 \mathrm{mM}$ alcohol on rat MCA diameter was compared with the effect of $50 \mathrm{mM}$ alcohol in mixture with $45 \mu \mathrm{M}$ celastrol using a cranial window in anesthetized rats. Following a baseline image recording of MCA diameter prior to any drug infusion, bolus injections of drugs of interest were performed toward the cerebral circulation via an intracarotid artery catheter. Infusion of $50 \mathrm{mM}$ ethanol, a concentration reached in blood during moderate-heavy alcohol drinking, caused a significant constriction of rat MCA 3 minutes after the initiation of the intracarotid infusion when diameter values reached $0.78 \pm$ 0.07 of control $(P<0.05)$. This result is shown with representative images (Fig. 7A, top panels) and averaged data (Fig. 7B, hollow circles). More importantly, as found with isolated vessels, $45 \mu \mathrm{M}$ celastrol completely reverted the constriction evoked by $50 \mathrm{mM}$ ethanol in the live animals, regardless of whether celastrol was introduced before or after alcohol $(P<0.05)$ (Fig. 7A, bottom and middle panels, and Fig. 7B, black squares and black triangles). Thus, celastrol is able to both prevent and revert the MCA constriction evoked by toxicologically relevant concentrations of ethanol. Collectively, our data also indicate that local metabolism, binding to circulating factors, or putative interactions with the anesthetic agents used do not modify the efficacy of either alcohol or celastrol, nor do they modify their interaction.

\section{Discussion}

Our study demonstrates for the first time that celastrol is a cerebrovascular dilator both ex vivo and in vivo. To prove this, we respectively used pressurized, isolated MCA segments and a cranial window on pial arteries branching out of the MCA, two systems widely used to study cerebral artery physiology, pathology, and pharmacology, as the rat arterial circulation greatly matches that of humans (Lee, 1995). The efficacy of celastrol-induced dilation might be judged at first glance as mild, with a maximal increase in diameter of $~ 10 \%$ over predrug values. However, Poiseuille's law (Rushmer, 1972) establishes that flow is related to vessel radius (and thus diameter) by a power of 4; thus, our results indicate that celastrol at $\mathrm{E}_{\max }$ would evoke a robust increase (up to $49 \%$ ) in local blood flow.

Celastrol-induced MCA dilation is endothelium-independent, which becomes particularly relevant when cerebrovascular dilation is pursued under conditions that disrupt endothelial function, such as obesity. Notably, phase 1 clinical trials for celastrol as an antiobesity drug are underway (Liu et al., 2015). The vasodilating properties of celastrol could bring cerebrovascular benefits in addition to its hunger-curbing action (Liu et al., 2015) in patients with obesity. The fact that celastrol dilation of cerebral arteries is endotheliumindependent raises the possibility of therapeutic additivity with other celastrol actions shown in human cells, rats, and mice, such as its anti-inflammatory and antioxidant properties leading to protection of the endothelium, although such properties have usually been observed at $50 \mathrm{nM}-10$ $\mu \mathrm{M}$ celastrol (Allison et al., 2001; Pinna et al., 2004; Cascão et al., 2012; Zeng et al., 2018). For example, the antioxidant and anti-inflammatory properties of celastrol seem beneficial in a rat MCA ischemia model, with low milligram concentrations of the drug ameliorating neurologic deficit, brain edema, and infarction size by downregulating the expression of p-JNK, p-c-Jun, and NF- $\kappa \mathrm{B}$ (Li et al., 2012). Several Food and Drug Administration-approved agents used to counteract neurotoxicity and treat brain ischemia or, more specifically, stroke share key pharmacological actions with celastrol: edaravone, curcumin, and minoxicline all have antioxidant activities and counteract neuroinflammation (Cole et al., 2007; Wang et al., 2008, 2010; Lapchak and Zivin, 2009; Lapchak, 2011). Whether these agents are effective 
A



B


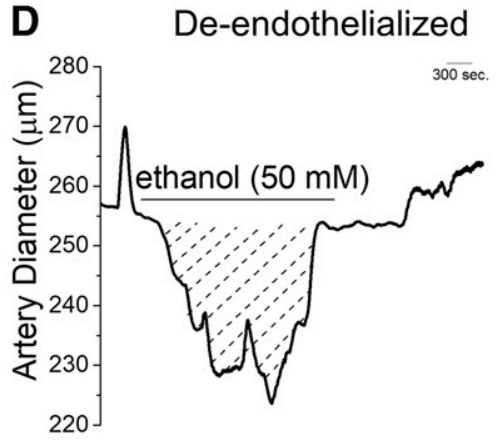

E

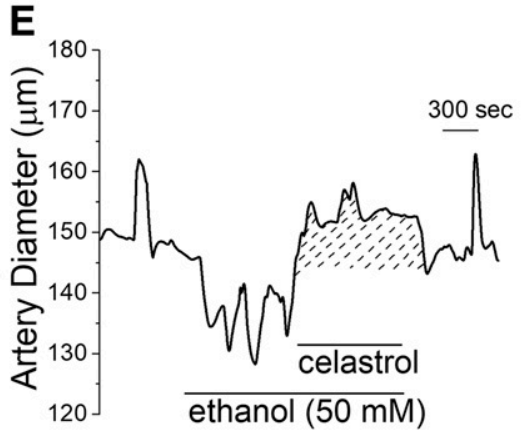

$\mathbf{F}$

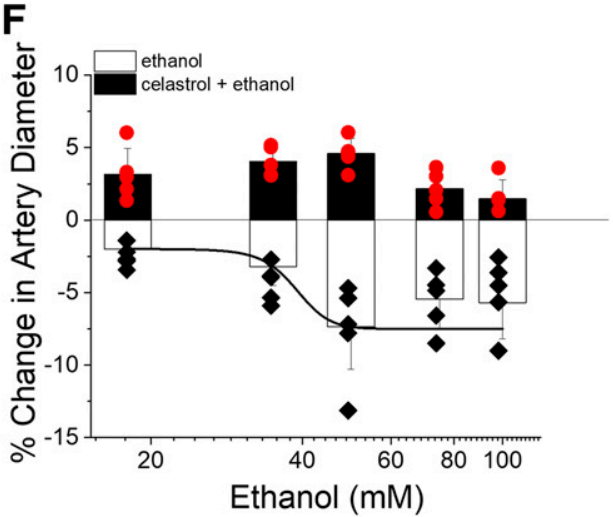

Fig. 6. Celastrol counteracts the ex vivo constriction of cerebral arteries evoked by a wide range of clinically relevant alcohol concentrations. (A) Diameter trace showing constriction of pressurized rat MCA segments with intact endothelium in the presence of $60 \mathrm{ml}$ of $50 \mathrm{mM}$ ethanol. (B) Diameter trace showing constriction of pressurized rat MCA segments with intact endothelium in the presence of $50 \mathrm{mM}$ ethanol followed by concurrent application of $50 \mathrm{mM}$ ethanol and $45 \mu \mathrm{M}$ celastrol. (C) Percent changes in rat MCA with intact endothelium in response to $50 \mathrm{mM}$ ethanol (black) immediately before addition of $45 \mu \mathrm{M}$ celastrol and in the presence of $50 \mathrm{mM}$ ethanol and $45 \mu \mathrm{M}$ celastrol mixture (red). (D) Diameter trace showing constriction of de-endothelialized rat MCA segments in the presence of $60 \mathrm{ml}$ of $50 \mathrm{mM}$ ethanol. (E) Diameter trace showing constriction of de-endothelialized rat MCA segments in the presence of $50 \mathrm{mM}$ ethanol followed by concurrent application of $50 \mathrm{mM}$ ethanol and $100 \mu \mathrm{M}$ celastrol. (F) Percent changes in rat MCA with intact endothelium in response to $50 \mathrm{mM}$ ethanol (black) immediately before addition of $100 \mu \mathrm{M}$ celastrol and in the presence of $50 \mathrm{mM}$ ethanol and $100 \mu \mathrm{M}$ celastrol mixture (red). cerebrovascular dilators like celastrol remains to be formally tested. If not, the availability of vasodilatory celastrol (or structural analogs; see below) may bring a considerable therapeutic advantage. Lastly, because cognition and other cerebral functions vitally depend on adequate blood perfusion, eventually determined by the diameter of resistance-size cerebral arteries (Cox and Rusch, 2002; Jackson, 2005; Moudgil et al., 2006), the possible additivity between celastrol's antioxidant/anti-inflammatory and vasodilating properties could have also contributed to data documenting that celastrol may improve performance in memory, learning, and psychomotor tests (Cascão et al., 2012) and be of benefit in treating Alzheimer, Parkinson, or Huntington disease (Allison et al., 2001; Cleren et al., 2005; Kiaei et al., 2005; Paris et al., 2010).

Our current study demonstrates that vasodilating concentrations of celastrol are able to both prevent and reverse ethanol-induced constriction of MCA, which proves for the first time that a drug targeting two distinct populations of SM $\mathrm{K}^{+}$channels is able to antagonize (both prevent and reverse) the cerebral artery response to ethanol concentrations reached in circulation during moderate-heavy binge drinking
(20-60 mM), the most common form of excessive alcohol consumption in the United States (https:/www.niaaa.nih. gov/alcohol-health/overview-alcohol-consumption/moderatebinge-drinking). Interestingly, celastrol's efficacy to evoke MCA dilation and antagonize alcohol action advances the pharmacological profile of an agent for which pharmacokinetic and bioavailability data are available, with oral administration of celastrol-containing tablets to rats having a $94.19 \%$ bioavailability (Zhang et al., 2012) and self-microemulsifying drug delivery systems for further optimization of celastrol bioavailability being already developed Qi et al., 201(Qi et al., 2014)4).

Based on MCA responses to celastrol in the presence of selective blockers, purely voltage-gated $\left(\mathrm{K}_{\mathrm{V}}\right)$ channels and $\mathrm{BK}$ channels of extraendothelial location (very likely in the vascular myocyte itself) are mediators of celastrol-induced cerebrovascular dilation, with each channel population being sufficient, yet none being necessary, to mediate drug action. Remarkably, the celastrol molecule includes several major structural features that are required for ligands of $\beta_{1}$ subunitcontaining BK channels, i.e., subunits that are particularly abundant in cerebrovascular SM (Dopico et al., 2018). These 
A
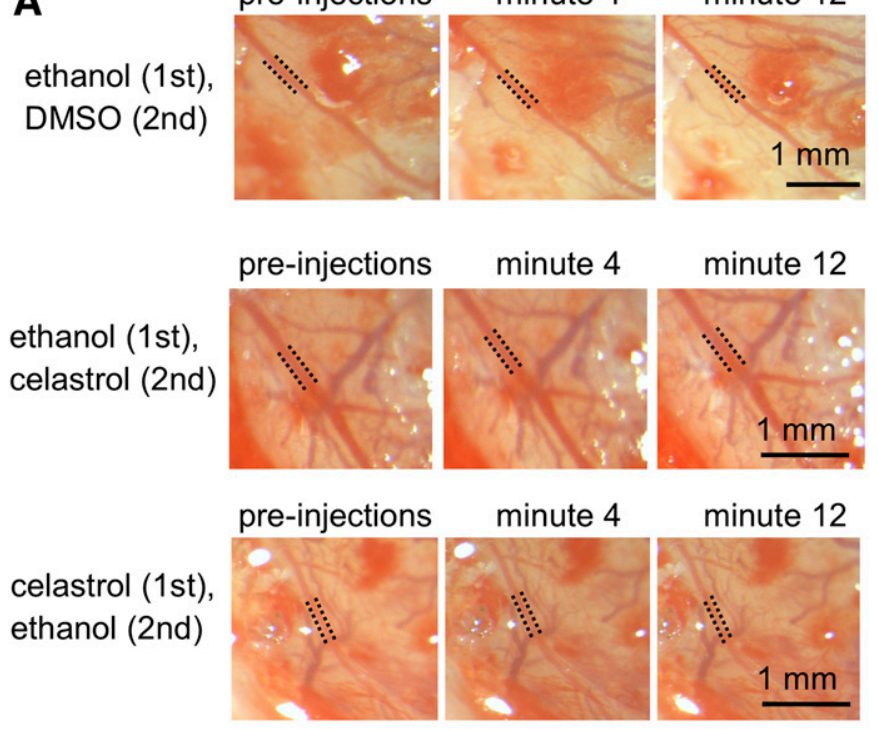

B

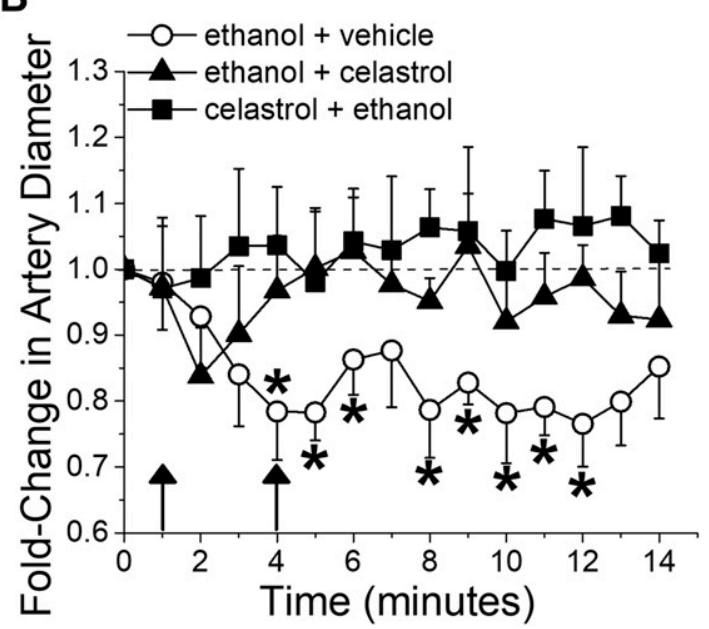

Fig. 7. Celastrol counteracts alcohol-induced cerebral artery constriction in vivo. (A) Cranial window images of rat MCA prior to any infusions (preinjections) at minute 1 , at minute 4 after infusions of either $50 \mathrm{mM}$ ethanol (top and middle rows of images) or time-matched $45 \mu \mathrm{M}$ celastrol (bottom row of images), and before the second injection of drug (either celastrol or ethanol), respectively. At minute 1, either a celastrol infusion was followed by a bolus infusion of $50 \mathrm{mM}$ ethanol (bottom row of images) or a $50 \mathrm{mM}$ ethanol infusion was followed by a bolus of $45 \mu \mathrm{M}$ celastrol (middle row of images). For comparison, animals from the alcohol-only group were followed by a time- and volume-matched infused with DMSO diluted in saline at minutes 1 and 4, respectively [images not shown; averaged data shown with circles in the plot in (B)]. Dashed lines highlight the area under the curve of MCA diameter change. (B) Fold changes in artery diameter for each minute of recording. $N=6$ for each group; individual $N$ was obtained from a separate rat. ${ }^{*}$ Different from alcohol infusion in presence of celastrol ( $P<0.05$, Mann-Whitney $U$ test).

structural features include a carboxylate group at one end of the celastrol molecule, a polar group (hydroxyl) at the other end, and a link between these two by a rather hydrophobic (usually poly-heterocyclic structure), as found in endogenous SM BK ligands such as bile acids (Dopico et al., 2002; Bukiya et al., 2011) and the synthetic compound termed "HENA" (Bukiya et al., 2013). Indeed, celastrol satisfies major pharmacophore criteria for $\beta_{1}$-containing BK channels (McMillan et al., 2014). Overall, celastrol maximal vasodilation ranges from $8 \%$ to $12 \%$ increase over predrug values when we consider all systems here studied: de-endothelialized and intact isolated MCA segments and cranial window MCA measurements in live rats. This ceiling overlaps with those of lithocholate (i.e., celastrol midrange of concentrations) and HENA (i.e., celastrol higher range of concentrations), as reported in both ex vivo and in vivo studies also conducted on rat MCA (Bukiya et al., 2007, 2013). We previously showed that both lithocholate- and HENA-induced MCA dilations, as demonstrated here by celastrol, were blunted by selective BK channel block (Bukiya et al., 2007, 2013; Liu et al., 2004). Celastrol's apparent affinity to dilate de-endothelialized MCA $\left(\mathrm{EC}_{50}=45 \mu \mathrm{M} ; \mathrm{E}_{\max } \leq 100 \mu \mathrm{M}\right)$, however, is higher than those of lithocholate or HENA $\left(\mathrm{EC}_{50}\right.$ values $=45-55 \mu \mathrm{M}$, and $\mathrm{E}_{\max }$ values $=100-300 \mu \mathrm{M})$, these values also being needed for lithocholate and HENA to increase SM BK channel activity (Bukiya et al., 2007, 2013), which suggests the involvement of SM targets additional to BK channels in celastrol action. In addition to BK channel activation, SM tone in cerebral arteries is critically reduced by the activity of $\mathrm{K}_{\mathrm{V}}$ channels (Faraci and Sobey, 1998). Indeed, our study shows that 4-AP at concentrations that block $K_{V}$ but not BK channels is capable of blunting celastrol-induced vasodilation. Given that separate application of $\mathrm{K}_{\mathrm{V}}$ and $\mathrm{BK}$ channel blockers equally blunts celastrol-induced vasodilation, it is possible to hypothesize that $\mathrm{K}^{+}$outflow-driven repolarization by either channel population is the common, primary mechanism that mediates celastrol dilation of de-endothelialized MCA. Remarkably, neither lithocholate- nor HENA-induced MCA dilations were significantly blunted by $\mathrm{K}_{\mathrm{V}}$ block (Bukiya et al., 2007, 2013). This leads us to speculate that under conditions that decrease SM BK channel function and compromise vasodilation (e.g., downregulation of $\beta_{1}$ subunit trafficking to the membrane, leading to desensitization to $\mathrm{Ca}^{2+}$ and functional uncoupling of $\mathrm{BK}$ channels from $\mathrm{Ca}^{2+}$ sparks, causing membrane depolarization, increase in SM tone, and arterial hypertension; Brenner et al., 2000; Plüger et al., 2000; Dopico et al., 2018; Bukiya et al., 2020), celastrol may remain efficacious via $\mathrm{K}_{\mathrm{V}}$ channel activation. Determination of the specific subunits, amino acids, and chemical bonds that could participate in celastrol-BK/K $\mathrm{K}_{\mathrm{V}}$ channel direct interactions exceeds the scope of the current study and will be addressed in the future.

Although our study unequivocally demonstrates that the endothelium is not required for celastrol-induced MCA dilation, some data suggest endothelial modulation of drug action: first, de-endothelialization causes a rightward shift in the concentration-response curve when compared with intact vessels (Fig. 2, B and D). Second, the ability of celastrol to counteract alcohol-induced constriction appears to be diminished in de-endothelialized arteries (Fig. 5). The identity of the endothelial mechanism(s) leading to fine-tune celastrol action on MCA diameter remains to be established. However, the facts that 1) celastrol $n_{\mathrm{H}}$ is $\sim 2$ in both intact and deendothelialized vessels and 2) blockade of celastrol by 4-AP and paxilline is undistinguishable under the two conditions suggest that endothelial factors do not exert a major modulation of celastrol action via $\mathrm{BK}$ and $\mathrm{K}_{\mathrm{V}}$ channels but that additional endothelial targets are involved.

In conclusion, we first document cerebrovascular dilation by celastrol, provide insights into the molecular mechanisms involved in this action, and advance clinically relevant scenarios for the use and application of the vasoactive properties of 
celastrol, including its antagonism of alcohol action on the cerebral circulation.

\section{Authorship Contributions}

Participated in research design: North, Bukiya, Dopico.

Conducted experiments: North, Slayden, Mysiewicz.

Performed data analysis: North, Bukiya, Dopico.

Wrote or contributed to the writing of the manuscript: North, Bukiya, Dopico.

\section{References}

Agrawal Y, Carey JP, Della Santina CC, Schubert MC, and Minor LB (2009) Disorders of balance and vestibular function in US adults: data from the National Health and Nutrition Examination Survey, 2001-2004. Arch Intern Med 169: 938-944.

Allison AC, Cacabelos R, Lombardi VRM, Alvarez XA, and Vigo C (2001) Celastrol, a potent antioxidant and anti-inflammatory drug, as a possible treatment for Alzheimer's disease. Prog Neuropsychopharmacol Biol Psychiatry 25:1341-1357.

Altszyler E, Ventura AC, Colman-Lerner A, and Chernomoretz A (2017) Ultrasensitivity in signaling cascades revisited: linking local and global ultrasensitivity estimations. PLoS One 12:e0180083.

Altura BM (1984) Alcohol, stroke, hypertension and the heart. Introduction and overview. Alcohol 1:321-323.

Altura BM and Altura BT (1984) Alcohol, the cerebral circulation and strokes. Alcohol 1:325-331.

Altura BM, Altura BT, and Gebrewold A (1983) Alcohol-induced spasms of cerebral blood vessels: relation to cerebrovascular accidents and sudden death. Science 220: 331-333.

Anderson P, Cremona A, Paton A, Turner C, and Wallace P (1993) The risk of alcohol. Addiction 88:1493-1508.

Baumbach GL and Heistad DD (1985) Regional, segmental, and temporal heterogeneity of cerebral vascular autoregulation. Ann Biomed Eng 13:303-310.

Beaglehole R and Jackson R (1992) Alcohol, cardiovascular diseases and all causes of death: a review of the epidemiological evidence. Drug Alcohol Rev 11:275-289.

Bentzen BH, Schmitt N, Calloe K, Dalby Brown W, Grunnet M, and Olesen SP (2006) The acrylamide (S)-1 differentially affects Kv7 (KCNQ) potassium channels. Neuropharmacology 51:1068-1077.

Brayden JE and Nelson MT (1992) Regulation of arterial tone by activation of calcium-dependent potassium channels. Science 256:532-535.

Brenner Robert, Perez Guillermo, Bonev Adrian, Eckman Delrae, Kosek Jon, Wiler Steven, Patterson Andrew, Nelson Mark, Aldrich Richard, et al. (2000) Vasoregulation by the $\beta 1$ subunit of the calcium-activated potassium channel. Nature 407:870-876

Brown RD Jr. (1999) Management of hypertensive patients with cerebrovascular disease. Hypertension Primer 2nd edition 396-401 In press.

Bukiya AN, Liu J, and Dopico AM (2009) The BK channel accessory beta1 subunit determines alcohol-induced cerebrovascular constriction. FEBS Lett 583: $2779-2784$.

Bukiya AN, Liu J, Toro L, and Dopico AM (2007) Beta1 (KCNMB1) subunits mediate lithocholate activation of large-conductance $\mathrm{Ca} 2+$-activated $\mathrm{K}+$ channels and dilation in small, resistance-size arteries. Mol Pharmacol 72:359-369.

Bukiya AN, McMillan JE, Fedinec AL, Patil SA, Miller DD, Leffler CW, Parrill AL and Dopico AM (2013) Cerebrovascular dilation via selective targeting of the cholane steroid-recognition site in the BK channel $\beta 1$-subunit by a novel nonsteroidal agent. Mol Pharmacol 83:1030-1044.

Bukiya AN, Singh AK, Parrill AL, and Dopico AM (2011) The steroid interaction site in transmembrane domain 2 of the large conductance, voltage- and calcium-gated potassium (BK) channel accessory $\beta 1$ subunit. Proc Natl Acad Sci USA 108 : 20207-20212.

Bukiya Anna, Leo DM, Jaggar JH, Dopico AM, et al. (2020) Cholesterol-induced Trafficking of beta1 Subunits Switches Modulation of BK Function by this Steroid from Inhibition to Activation. Biophysical Journal 118 (3):109A-110A.

Busija DW and Leffler CW (1991) Selective attenuation by perivascular blood of prostanoid-dependent cerebrovascular dilation in piglets. Stroke 22:484-488.

Cascão R, Vidal B, Raquel H, Neves-Costa A, Figueiredo N, Gupta V, Fonseca JE, and Moita LF (2012) Effective treatment of rat adjuvant-induced arthritis by celastrol. Autoimmun Rev 11:856-862.

Cipolla MJ and Curry AB (2002) Middle cerebral artery function after stroke: the threshold duration of reperfusion for myogenic activity. Stroke 33:2094-2099.

Cleren C, Calingasan NY, Chen J, and Beal MF (2005) Celastrol protects against MPTP- and 3-nitropropionic acid-induced neurotoxicity. $J$ Neurochem 94: 995-1004.

Cole GM, Teter B, and Frautschy SA (2007) Neuroprotective effects of curcumin. Adv Exp Med Biol 595:197-212.

Cox RH and Rusch NJ (2002) New expression profiles of voltage-gated ion channels in arteries exposed to high blood pressure. Microcirculation 9:243-257.

Cudd TA, Chen WJA, and West JR (1996) Acute hemodynamic, pituitary, and adrenocortical responses to alcohol in adult female sheep. Alcohol Clin Exp Res 20 $1675-1681$.

Diamond I (1992) Cecil Textbook of Medicine pp 44-47, Saunders, Philadelphia.

Dopico Alejandro, Walsh John, Singer Joshua, et al. (2002) Natural Bile Acids and Synthetic Analogues Modulate Large Conductance $\mathrm{Ca}^{2+}$-activated $\mathrm{K}^{+}\left(\mathrm{BK}_{\mathrm{Ca}}\right)$ Channel Activity in Smooth Muscle Cells. Journal of General Physiology 119 (3): 251-273 In press.

Dopico AM, Bukiya AN, and Jaggar JH (2018) Calcium- and voltage-gated BK channels in vascular smooth muscle. Pflugers Arch 470:1271-1289.
Dopico AM and Lovinger DM (2009) Acute alcohol action and desensitization of ligand-gated ion channels. Pharmacol Rev 61:98-114.

Edmeads J (1977) Cerebral blood flow in migraine. Headache 17:148-152.

Faraci FM and Sobey CG (1998) Role of potassium channels in regulation of cerebral vascular tone. J Cereb Blood Flow Metab 18:1047-1063.

Fernández-Solà $J$ (2015) Cardiovascular risks and benefits of moderate and heavy alcohol consumption. Nat Rev Cardiol 12:576-587.

Fonseca AC and Ferro JM (2013) Drug abuse and stroke. Curr Neurol Neurosci Rep 13:325.

González Delgado M and Bogousslavsky J (2012) Superficial middle cerebral artery territory infarction. Front Neurol Neurosci 30:111-114.

Gordon SE and Zagotta WN (1995) Localization of regions affecting an allosteric transition in cyclic nucleotide-activated channels. Neuron 14:857-864.

Hansen JB (2006) Towards selective Kir6.2/SUR1 potassium channel openers, medicinal chemistry and therapeutic perspectives. Curr Med Chem 13:361-376.

Hui F, Nguyen CTO, He Z, Vingrys AJ, Gurrell R, Fish RL, and Bui BV (2017) Retinal and cortical blood flow dynamics following systemic blood-neural barrier disruption. Front Neurosci 11:568.

Jackson WF (2005) Potassium channels in the peripheral microcirculation. Microcirculation 12:113-127.

Jensen BS (2002) BMS-204352: a potassium channel opener developed for the treatment of stroke. CNS Drug Rev 8:353-360.

Kamouchi M, Kitazono T, Nagao T, Fujishima M, and Ibayashi S (2002) Role of $\mathrm{CA}(2+)$-activated $\mathrm{K}+$ channels in the regulation of basilar arterial tone in spontaneously hypertensive rats. Clin Exp Pharmacol Physiol 29:575-581.

Kiaei M, Kipiani K, Petri S, Chen J, Calingasan NY, and Beal MF (2005) Celastrol blocks neuronal cell death and extends life in transgenic mouse model of amyotrophic lateral sclerosis. Neurodegener Dis 2:246-254.

Kim S, Kim JH, Jeon O, Kwon IC, and Park K (2009) Engineered polymers for advanced drug delivery. Eur J Pharm Biopharm 71:420-430.

Klatsky AL (2015) Alcohol and cardiovascular diseases: where do we stand today? J Intern Med 278:238-250.

Krafft PR, Bailey EL, Lekic T, Rolland WB, Altay O, Tang J, Wardlaw JM, Zhang JH, and Sudlow CL (2012) Etiology of stroke and choice of models. Int $J$ Stroke 7: $398-406$

Lapchak PA (2011) Neuroprotective and neurotrophic curcuminoids to treat stroke: a translational perspective. Expert Opin Investig Drugs 20:13-22.

Lapchak PA and Zivin JA (2009) The lipophilic multifunctional antioxidant edaravone (radicut) improves behavior following embolic strokes in rabbits: a combination therapy study with tissue plasminogen activator. Exp Neurol 215:95-100.

Lauritzen M, Skyhøj Olsen T, Lassen NA, and Paulson OB (1983) Changes in regional cerebral blood flow during the course of classic migraine attacks. Ann Neurol 13:633-641.

Lee RM (1995) Morphology of cerebral arteries. Pharmacol Ther 66:149-173.

Lehecka M, Dashti R, Rinne J, Romani R, Kivisaari R, Niemelä M, and Hernesniem $J$ (2012) Surgical management of aneurysms of the middle cerebral artery, in Schmidek and Sweet: Operative Neurosurgical Techniques: Indications, Methods and Results, 6th ed (Quinones-Hinojosa A 897-913, Saunders, Cambridge, MA

Li Y, He D, Zhang X, Liu Z, Zhang X, Dong L, Xing Y, Wang C, Qiao H, Zhu C, et al. (2012) Protective effect of celastrol in rat cerebral ischemia model: down-regulating p-JNK, p-c-Jun and NF-кB. Brain Res 1464:8-13.

Liu J, Lee J, Salazar Hernandez MA, Mazitschek R, and Ozcan U (2015) Treatment of obesity with celastrol. Cell 161:999-1011.

Liu P, Xi Q, Ahmed A, Jaggar JH, and Dopico AM (2004) Essential role for smooth muscle BK channels in alcohol-induced cerebrovascular constriction. Proc Nat Acad Sci USA 101:18217-18222.

Ma X, Xu L, Alberobello AT, Gavrilova O, Bagattin A, Skarulis M, Liu J, Finkel T, and Mueller E (2015) Celastrol protects against obesity and metabolic dysfunction through activation of a HSF1-PGC1 $\alpha$ transcriptional axis. Cell Metab 22:695-708.

Macdonald LR and Weir B (2001) Cerebral Vasospasm, Academic Press, Cambridge, MA.

Mannhold $\mathrm{R}$ (2004) $\mathrm{K}_{\mathrm{ATP}}$ channel openers: structure-activity relationships and therapeutic potential. Med Res Rev 24:213-266.

McMillan JE, Bukiya AN, Terrell CL, Patil SA, Miller DD, Dopico AM, and Parrill AL (2014) Multi-generational pharmacophore modeling for ligands to the cholane steroid-recognition site in the $\beta_{1}$ modulatory subunit of the BKCa channel. $J \mathrm{Mol}$ Graph Model 54:174-183.

Moudgil R, Michelakis ED, and Archer SL (2006) The role of $k+$ channels in determining pulmonary vascular tone, oxygen sensing, cell proliferation, and apoptosis: implications in hypoxic pulmonary vasoconstriction and pulmonary arterial hypertension. Microcirculation 13:615-632.

Nardi A and Olesen SP (2008) BK channel modulators: a comprehensive overview. Curr Med Chem 15:1126-1146.

North KC, Chang J, Bukiya AN, and Dopico AM (2018) Extra-endothelial TRPV1 channels participate in alcohol and caffeine actions on cerebral artery diameter. Alcohol 73:45-55.

Olesen J, Lauritzen M, Tfelt-Hansen P, Henriksen L, and Larsen B (1982) Spreading cerebral oligemia in classical- and normal cerebral blood flow in common migraine. Headache 22:242-248.

Paris D, Ganey NJ, Laporte V, Patel NS, Beaulieu-Abdelahad D, Bachmeier C, March A, Ait-Ghezala G, and Mullan MJ (2010) Reduction of beta-amyloid pathology by celastrol in a transgenic mouse model of Alzheimer's disease. J Neuroinflammation 7:17.

Pinna GF, Fiorucci M, Reimund JM, Taquet N, Arondel Y, and Muller CD (2004) Celastrol inhibits pro-inflammatory cytokine secretion in Crohn's disease biopsies. Biochem Biophys Res Commun 322:778-786.

Plüger S, Faulhaber J, Fürstenau M, Löhn M, Waldschütz R, Gollasch M, Haller H, Luft FC, Ehmke $\mathrm{H}$, and Pongs $\mathrm{O}(2000)$ Mice with disrupted BK channel beta1 subunit gene feature abnormal $\mathrm{Ca}(2+)$ spark/STOC coupling and elevated blood pressure. Circ Res 87:E53-E60. 
Qi Xiaole, Qin Jiayi, Ma Ning, Chou Xiaohua, Wu Zhenghong, et al. (2014) Solid selfmicroemulsifying dispersible tablets of celastrol: formulation development, charaterization and bioavailability evaluation. International Journal of Pharmaceutics 472 (1-2):40-47 Published ahead of print.

Ramos-Cabrer P, Campos F, Sobrino T, and Castillo J (2011) Targeting the ischemic penumbra. Stroke 42 (1 Suppl):S7-S11.

Reynolds K, Lewis B, Nolen JD, Kinney GL, Sathya B, and He J (2003) Alcohol consumption and risk of stroke: a meta-analysis [published correction appears in JAMA (2003) 289:2798]. JAMA 289:579-588.

Richardson EP Jr. and Dodge PR (1954) Epilepsy in cerebral vascular disease a study of the incidence and nature of seizures in 104 consecutive autopsy-proven cases of cerebral infarction and hemorrhage. Epilepsia 3:49-74.

Robertson BE and Nelson MT (1994) Aminopyridine inhibition and voltage dependence of $\mathrm{K}+$ currents in smooth muscle cells from cerebral arteries. Am $J$ Physiol 267:C1589-C1597.

Román GC (2003) Stroke, cognitive decline and vascular dementia: the silent epidemic of the 21st century. Neuroepidemiology 22:161-164.

Rushmer Robert (1972) Organ physiology: structure and function of the cardiovas cular system, Saunders.

Schreiber SJ, Doepp F, Spruth E, Kopp UA, and Valdueza JM (2005) Ultrasonographic measurement of cerebral blood flow, cerebral circulation time and cerebral blood volume in vascular and Alzheimer's dementia. J Neurol 252:1171-1177.

Simakova MN, Zaytseva D, Bisen S, Dopico AM, and Bukiya AN (2017) Role of the slo1 CRAC4 motif in BK channel's ethanol sensitivity. Biophys J 112:112a.

Strøbaek D, Christophersen P, Holm NR, Moldt P, Ahring PK, Johansen TE, and Olesen SP (1996) Modulation of the $\mathrm{Ca}(2+)$-dependent $\mathrm{K}+$ channel, hslo, by the substituted diphenylurea NS 1608, paxilline and internal Ca2+. Neuropharmacology 35:903-914.

Villarreal AE, Barron R, Rao KS, and Britton GB (2014) The effects of impaired cerebral circulation on Alzheimer's disease pathology: evidence from animal studies. J Alzheimers Dis 42:707-722.

Villella E and Cho JS (2015) Effect of aging on the vascular system plus monitoring and support. Surg Clin North Am 95:37-51.
Wang R, Li YB, Li YH, Xu Y, Wu HL, and Li XJ (2008) Curcumin protects against glutamate excitotoxicity in rat cerebral cortical neurons by increasing brainderived neurotrophic factor level and activating TrkB. Brain Res 1210:84-91.

Wang R, Li YH, Xu Y, Li YB, Wu HL, Guo H, Zhang JZ, Zhang JJ, Pan XY, and Li XJ (2010) Curcumin produces neuroprotective effects via activating brain-derived neurotrophic factor/TrkB-dependent MAPK and PI-3K cascades in rodent cortical neurons. Prog Neuropsychopharmacol Biol Psychiatry 34:147-153.

Wilkinson IB and Cockcroft JR (1998) Cholesterol, endothelial function and cardiovascular disease. Curr Opin Lipidol 9:237-242.

Yang ZW, Wang J, Zheng T, Altura BT, and Altura BM (2001) Ethanol-induced contractions in cerebral arteries: role of tyrosine and mitogen-activated protein kinases. Stroke 32:249-257.

Zakhari S (1997) Alcohol and the cardiovascular system: molecular mechanisms for beneficial and harmful action. Alcohol Health Res World 21:21-29.

Zeng Z, Lin X, Zheng R, Zhang H, and Zhang W (2018) Celastrol alleviates airway hyperresponsiveness and inhibits Th17 responses in obese asthmatic mice. Front Pharmacol 9:49.

Zhang A, Altura BT, and Altura BM (1993) Ethanol-induced contraction of cerebral arteries in diverse mammals and its mechanism of action. Eur $J$ Pharmacol 248: $229-236$.

Zhang Jun, Li Chang-Yin, Xu Mei-juan, Wu Ting, Chu Ji-hong, Liu Shi-Jia, Ju WenZheng, et al. (2012) Oral bioavailability and gender-related pharmacokinetics of celastrol following administration of pure celastrol and its related tablets in rats. Journal of Ethnopharmacology In press.

Zhou Y and Lingle CJ (2014) Paxilline inhibits BK channels by an almost exclusively closed-channel block mechanism. J Gen Physiol 144:415-440.

Address correspondence to: Dr. Alex Dopico, Department of Pharmacology, Addiction Science and Toxicology, College of Medicine, The University of Tennessee Health Science Center, 71 S. Manassas St, Room \#231, Memphis, TN 38163. E-mail: adopico@uthsc.edu 